\title{
Minilaparotomy hysterectomy Versus laparoscopic hysterectomy for benign uterine lesions A Comparative study
}

\section{Ayman El-Dorf}

Obstetrics and Gynecology Department, Faculty of Medicine, Tanta University. Tanta, Egypt.

Corresponding Author: Ayman El-Dorf, Obstetrics and Gynecology Department, Faculty of Medicine, Tanta University. Tanta, Egypt.

Received Date: November 14, 2020; Accepted Date: November 24, 2020; Published Date: November 30, 2020

Citation: Ayman El-Dorf (2020) Minilaparotomy hysterectomy Versus laparoscopic hysterectomy for benign uterine lesions A Comparative study. J Women Health Care Issues, 3(4); Doi:10.31579/2642-9756/037

Copyright: $\odot 2020$ Ayman El-Dorf, This is an open-access article distributed under the terms of the Creative Commons Attribution License, which permits unrestricted use, distribution, and reproduction in any medium, provided the original author and source are credited.

\begin{abstract}
:
Background: Hysterectomy is world wide's second most commonly done gynecological surgery, second only to the caesarean section. There is no general consensus, however, about the optimal hysterectomy process. Hysterectomy may be achieved through different techniques such as stomach, vaginal and laparoscopic.

The goal of the study is to explore whether the hysterectomy of minilaparotomy for benign uterine lesions may be a viable option to laparoscopic hysterectomy in terms of short-term operational and postoperative performance.

Methods: 105 patients who were due to undergo complete hysterectomy for a benign uterine lesion were split into 3 categories according to their preference of therapeutic therapy method: group A (35 patients) minilaparotomy hysterectomy utilizing traditional sutures. Group B (35 patients) minilaparotomy hysterectomy utilizing bipolar vessel sealing procedure (Ligasure). Group C (35patients) laparoscopic hysterectomy using Ligasure.

Result (s): The operating time in Group A (84.71 \pm 9.91 minutes), group B (55.31 \pm 7.81 minutes), while group C (94.81 \pm 16.1 minutes). The duration until resumption of intestinal sounds in group $\mathrm{C}(12.31 \pm 2.51$ hours $)$ in comparison to group $\mathrm{A}$ (17.41 \pm 1.91 hours) and group B (16.51 \pm 1.761 hours $)$. Blood loss in group B (99.11 $\pm 30.81 \mathrm{ml})$, group A (130.31 \pm 54.41 $\mathrm{ml})$ and group $\mathrm{C}(136.61 \pm 6.61 \mathrm{ml})$. The longest hospital stay occurred in group A (31.8 $1 \pm 5.71$ hours) versus groups B (20.71 \pm 2.51 hours) and $\mathrm{C}(19.31 \pm 6.1$ hours). The highest pain score was observed in group $\mathrm{A}(5.21 \pm 1.11)$ versus groups $\mathrm{B}$ (3.81 $\pm 1.61)$ and $C(3.71 \pm 1.21)$. There was no significant difference in the incidence of intraoperative or postoperative complications.

Conclusion (s): Less operational time and intraoperative blood loss were correlated with the usage of ligasure bipolar vessel sealing device in minilaparotomy hysterectomy, whereas it was comparable to laparoscopic hysterectomy in hospital stay and low morbidity postoperative pain scoring and a limited hospital stay. It can be an acceptable alternative to laparoscopic hysterectomy, suitable in areas without laparoscopic experience or facilities.
\end{abstract}

Key words: hysterectomy; Surgical incision

\section{Introduction}

Laparoscopic hysterectomy has uncovered broad enticing horizons in minimally invasive procedure, providing outstanding outcomes for both the surgeon and the patient in terms in pre- and post-operative performance. In fact, patients undergoing surgical laparoscopy showed excellent surgical results, shorter hospitalization, quicker recovery, and improved quality of life compared to traditional abdominal hysterectomy usually performed by a Pfannenstiel incision [1,2].

Minilaparotomy hysterectomy is characterized as a hysterectomy done through a transverse incision of the abdomen into the upper level of the pubic hair not longer than $6 \mathrm{~cm}$ long. First used in 1995 by Dr. Marco A. Pelosi II, this procedure is claimed to incorporate the technological benefits of regular laparotomy (e.g. faster learning curve) with the convalescent benefits of laparoscopy (e.g. low morbidity) So, it could be an alternative to laparoscopic hysterectomy $[3,4]$.

Aim of the work:

The goal of the study is to explore whether the hysterectomy of minilaparotomy for benign uterine lesions may be a viable option to laparoscopic hysterectomy in terms of short-term operational and postoperative performance.

\section{Patients and methods:}

This prospective non-randomized clinical trial was performed between January 2017 and May 2020 in the Department of Obstetrics and Gynecology Tanta university hospitals This research involved 105 patients expected to undergo complete abdominal hysterectomy, with or without bilateral salpingoophorectomy. 
Group A (35 patients) will undergo minilaparotomy hysterectomy using conventional sutures.

Group B (35 patients) will undergo minilaparotomy hysterectomy using bipolar vessel sealing system (LigaSure).

Group C (35 patients) will undergo laparoscopic hysterectomy using LigaSure.

All patients were scheduled to undergo hysterectomy for a benign uterine lesion

\section{Exclusion criteria:}

- Severe cardiopulmonary disorder precluding role in Trendlenburg.

- Any suspects or confirmations of uterine malignancy.

- Uterine scale $>12$ weeks pregnancy.

- Uterine immobility owing to 2 or more prior laparotomies, pelvic endometriosis, or other conditions such as persistent inflammatory pelvic disorder.

- The masses of adnexal.

- $\quad \mathrm{BMI}>35 \mathrm{k} / \mathrm{m} 2$

\section{Methods:}

Method of intervention was adopted according to patient's desire. Appropriate informative consent was obtained from the patient after a thorough explanation and description of the planned procedure, its potential risks and benefits, and the possibility of conversion to laparotomy in the laparoscopic group. Patients are informed that general anesthesia will be used with proper explanation of the procedure and its potential risks by the anesthesiologist.

Full history taking, gynecologic examination and ultrasound examination were done to all patients.

The following data were collected from every patient in all groups:

- $\quad$ Age.

- BMI.

- Operative time.

- Estimated intraoperative blood loss:

1. During minilaparotomy, the fully soaked laparotomy pad (30 $\times 30 \mathrm{~cm}$ ) means about $100-150 \mathrm{cc}$ blood loss and the soaked surgical sponge $(4 \times 4 \mathrm{~cm})$ means about $10 \mathrm{cc}$ and the amount of blood in suction container is added.

2. During laparoscopy the amount of blood loss was estimated by the amount in the suction container after subtracting the amount of fluid used for washing.

- Preoperative hemoglobin and postoperative hemoglobin deficit 12 hours after surgery.

- Any intraoperative complications like urinary or intestinal injuries.

- Time to resumption of bowel movements to normal.
- Pain score through 12 hours postoperative period according to revised face pain scale.

- Length of hospital stay.

- Post-operative complications.

Patients in the laparoscopic community are recommended to use only oral beverages in the last 2 days previous to operation, although this is not the norm with the minilaparotomy classes. It is recommended that all patients in the three classes will fast 12 hours before surgery. There are two adversaries of the fleet; one the night before and the other two hours before the operation.

Routine pre-operative examinations were conducted on each patient including: $\mathrm{CBC}$, coagulation profile, FBS, screening of hepatitis receptors, liver and kidney function checks, and ECG. Patients of certain medical conditions require further examination from a general practitioner who can prescribe further laboratory testing if appropriate. Service is performed in the morning. Patient must arrive at least 2 hours before surgery to give the anesthesiologist enough time to review the patient's condition and the findings of their laboratory.

General anesthesia is used and prophylactic antibiotics are given in the form of 2 grams of cefotaxime and is replicated as one gram 12 hours after surgery.

After the procedure, both patients are offered intramuscular analgesia in the form of meperidine (pethidine) injection of $50 \mathrm{mg}$ once plus diclophenac sodium (Voltaren $75 \mathrm{mg}$ ampoule) twice 12 hours apart. In certain cases, further analgesia is required. After reporting bowel movements accompanied by semisolid fluids oral fluids commence as soon as possible. Patients can go home while they are outpatient, transfer, passing urine and gas normally without complications. Patients are provided a phone number available 24 hours a day upon discharge. Follow-up appointments are planned after one week, and then after one month. Thromboprophylaxis in the form of 40-60 mg Enoxaparin (Clexane) is administered 6-12 hours postoperatively as SC injections, and every 24 hours for 3-5 days in all patients in the laparoscopy community and in patients with BMI $>30 \mathrm{~kg} / \mathrm{m} 2$ in minilaparotomy groups.

\section{Statistical analysis:}

Statistical analysis was performed using the Statistical Package for Social Science for Windows (SPSS, Inc., Chicago, IL) version 14.

\section{Results:}

As shown in table [1], the mean age of group A (minilaparotomy hysterectomy with conventional sutures) was $50.51 \pm 4.41$ years old. The mean age of group B (minilaparotomy hysterectomy with LigaSure) was $49.21 \pm 3.81$ years old and the mean age of group C (laparoscopic group) was $50.21 \pm 4.41$ years old.

\begin{tabular}{|c|c|c|c|c|c|}
\hline & $\mathbf{A}$ & B & $\mathbf{C}$ & $\mathbf{F}$ & $\mathbf{P}$ \\
\hline \multicolumn{6}{|l|}{ Age (years) } \\
\hline Mean \pm SD & $50.51 \pm 4.41$ & $49.21 \pm 3.81$ & $50.21 \pm 4.41$ & 0.87 & 0.41 \\
\hline Range & $43-60$ & $43-59$ & $42-58$ & & \\
\hline \multicolumn{6}{|l|}{ BMI $\left(\mathrm{kg} / \mathbf{m}^{2}\right)$} \\
\hline Mean \pm SD & $28.11 \pm 2.21$ & $27.7 \pm 2.21$ & $29.71 \pm 2.61$ & 6.6 & 0.0019 \\
\hline Range & $23.2-32.2$ & $23-31.3$ & $23-34.95$ & & \\
\hline
\end{tabular}

Table 1: The preoperative demographic data for all of our patie

The $\mathrm{p}$ value in age was not significant. As regard BMI, in group A, the mean of BMI was $28.11 \pm 2.21 \mathrm{~kg} / \mathrm{m} 2$. In group B (minilaparotomy hysterectomy with LigaSure), the mean of BMI was $27.71 \pm 2.21 \mathrm{~kg} / \mathrm{m} 2$. In group C (laparoscopic group), the mean of BMI was $29.71 \pm 2.61$ 
$\mathrm{kg} / \mathrm{m} 2$. The $\mathrm{p}$ value of the body mass index was important with group $\mathrm{C}$ providing the lowest BMI relative to groups A and B. The symptoms of hysterectomy in this sample were mostly mild conditions: fibroid uterus less than or equivalent to 12 weeks gestation, endometrial hyperplasia, abnormal uterine bleeding not leading to medical attention, and possible adenomyosis. Many of these signs are seen in table [2] Which shows that: in the signs, all classes were almost identical. Fibroid uterus accounted for 48.61 percent in group A (minilaparotomy hysterectomy with traditional sutures), 48.61 percent in group B (minilaparotomy hysterectomy with LigaSure) and 51.41 percent in group C (laparoscopic group).

\begin{tabular}{|c|c|c|c|c|c|c|}
\hline & \multicolumn{2}{|c|}{ A } & \multicolumn{2}{c|}{ B } & \multicolumn{2}{c|}{ C } \\
\cline { 2 - 6 } & No & \% & No & \% & No & \% \\
\hline Fibroid & 17 & 48.6 & 17 & 48.6 & 18 & 51.4 \\
\hline Adenomyosis & 4 & 11.4 & 5 & 14.3 & 4 & 11.4 \\
\hline DUB & 7 & 20 & 7 & 20 & 3 & 8.6 \\
\hline Endometrial hyperplasia & 7 & 20 & 6 & 17.1 & 9 & 25.7 \\
\hline Endometrial polyp & 0 & 0 & 0 & 0 & 1 & 2.9 \\
\hline
\end{tabular}

Table 2: Indications

Suspected adenomyosis accounted for 11.41 percent (4 cases) of category A (minilaparotomy hysterectomy with traditional sutures), $14.31 \%$ (5 cases) in group B (minilaparotomy hysterectomy with LigaSure) and $11.41 \%$ (8 cases) in group C (laparoscopic group).

Dysfunctional uterine Bleeding (DUB) accounted for 20 per cent of group A cases, 20 per cent of group $B$ cases and 8.61 per cent of group $C$ cases

Endometrial hyperplasia also accounted for 20 per cent of cases in Group A (minilaparotomy hysterectomy with traditional sutures), 17.11 per cent of cases in Group B and $25.71 \%$ of cases in group C

As shown in table (3), there was a highly significant difference in the operating time among the 3 groups with the shortest time being observed in group B and the longest time in group C. Group A (minilaparotomy hysterectomy with conventional sutures) took $84.71 \pm 9.91$ minutes,

\begin{tabular}{|c|c|c|c|c|c|c|}
\hline & A & B & C & F & p \\
\hline \multicolumn{7}{|c|}{ Operative time (minutes) } \\
\hline Mean \pm SD & $84.71 \pm 9.91$ & $55.31 \pm 7.81^{*}$ & $94.81 \pm 16.1$ & 38.5 & $<0.001$ \\
\hline Range & $65-105$ & $45-75$ & $65-135$ & & \\
\hline Mean \pm SD & $130.31 \pm 54.41$ & $99.11 \pm 30.81^{*}$ & $128.61 \pm 6.61$ & 12.3 & $<0.001$ \\
\hline Range & $50-250$ & $50-150$ & $50-300$ & & \\
\hline
\end{tabular}

*Group B versus A and C

Table 3: Operative time and estimated blood loss

\begin{tabular}{|c|c|c|c|c|c|}
\hline & A & B & C & F & P \\
\hline \multicolumn{7}{|c|}{ Bowel movements (hours) } \\
\hline Mean \pm SD & $17.41 \pm 1.91$ & $16.511 \pm 1.761$ & $12.31 \pm 2.51^{+}$ & 52.1 & $<0.001$ \\
\hline Range & $13-21$ & $12-18$ & $9-20$ & \\
\hline \multicolumn{7}{|c|}{ Hb deficit (gm/dl) } \\
\hline Mean \pm SD & $0.711 \pm 0.251$ & $0.49 \pm 0.21^{*}$ & $0.68 \pm 0.5$ & 9.64 & $0.0019^{*}$ \\
\hline Range & $0.21-1.21$ & $0.21-0.91$ & $0.2-2$ & & \\
\hline
\end{tabular}

* Group B versus A and C

${ }^{+}$Group C versus A and B

Table 4: Bowel movements and Hb deficit

\begin{tabular}{|c|c|c|c|c|c|}
\hline & A & B & C & F & P \\
\hline Hospital stay (hours) & & & & & \\
\hline Mean \pm SD & $31.81 \pm 5.71^{*}$ & $20.71 \pm 2.51$ & $19.311 \pm 6.1$ & 31.3 & $<0.001$ \\
\hline Range & $24-48$ & $18-26$ & $15-48$ & & \\
\hline Pain score & & & & & \\
\hline Mean \pm SD & $5.21 \pm 1.11^{*}$ & $3.81 \pm 1.61$ & $3.71 \pm 1.21$ & 11.49 & $<0.001$ \\
\hline Range & $4-8$ & $2-6$ & $2-6$ & & \\
\hline
\end{tabular}


Table 5: Hospital stay and pain score

\begin{tabular}{|c|c|c|c|c|c|c|c|c|}
\hline & \multicolumn{2}{|c|}{ A } & \multicolumn{2}{|c|}{ B } & \multicolumn{2}{|c|}{$\mathrm{C}$} & \multirow{2}{*}{$\mathbf{X}^{2}$} & \multirow{2}{*}{$\mathbf{P}$} \\
\hline & No & $\%$ & No & $\%$ & No & $\%$ & & \\
\hline No complications & 31 & 88.6 & 33 & 94.3 & 32 & 91.5 & 2.26 & 0.32 \\
\hline Seroma & 3 & 8.6 & 2 & 5.7 & 0 & 0 & 2.94 & 0.22 \\
\hline Stitch sinus & 1 & 2.8 & 0 & 0 & 0 & 0 & 2.02 & 0.36 \\
\hline Bladder injury & 0 & 0 & 0 & 0 & 1 & 2.8 & 4.08 & 0.13 \\
\hline Intraoperative Bleeding & 0 & 0 & 0 & 0 & 2 & 5.7 & 4.08 & 0.13 \\
\hline
\end{tabular}

Table 6: Complications

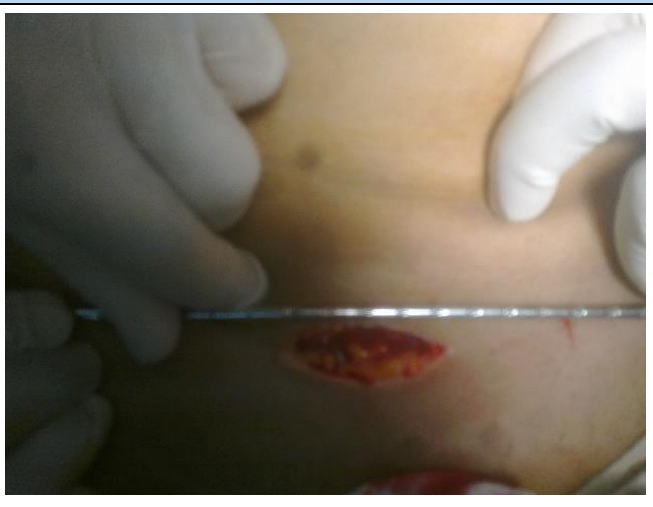

Skin incision

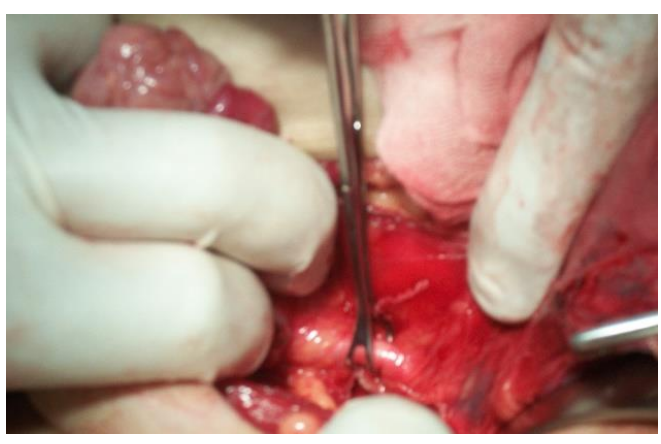

Identification of the ureter

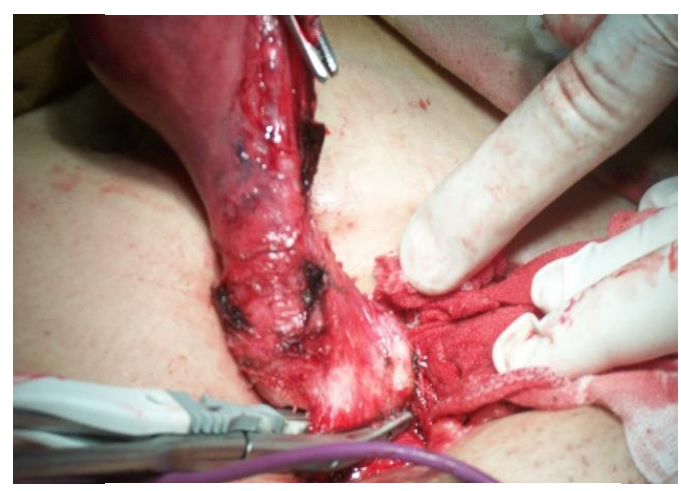

Removal of the uterine specimen

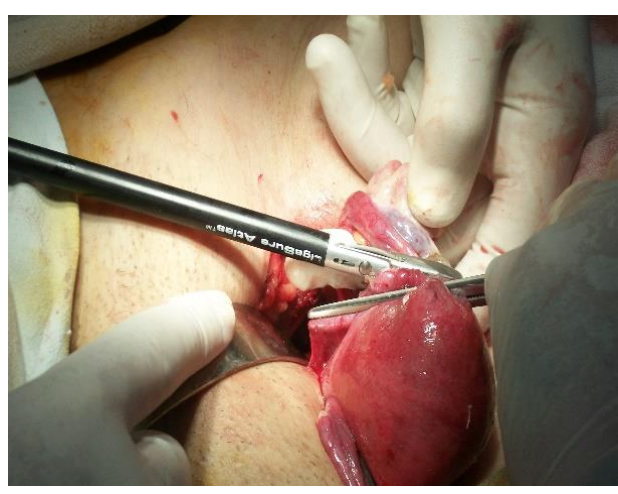

Utero-ovarian ligament securing with preservation of the

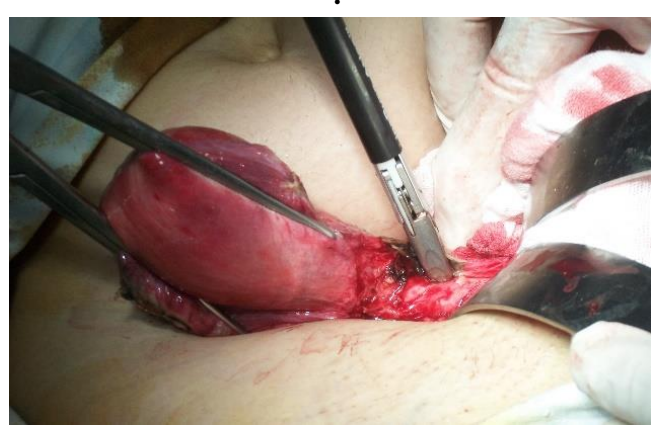

Securing uterine vessels

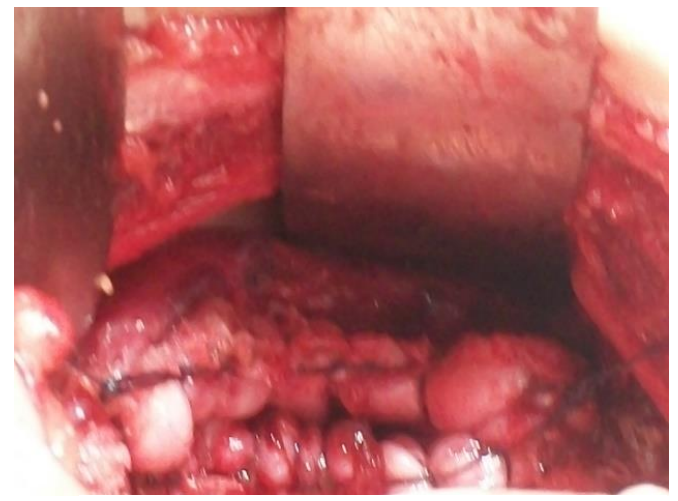

Open-cuff closure of the vault

Figure 1: Steps of minilaparotomy hysterectomy using LigaSure

There has been no clinically important increase in the occurrence of intraoperative or postoperative complications. With regard to intraoperative complications, there were two instances in group $\mathrm{C}$ (laparoscopic community) that suffered intraoperative bleeding without the need for blood transfusion. There was just one instance of bladder injury that happened in category $\mathrm{C}$ (laparoscopic community). 
With advancements in laparoscopic procedures, the bulk of hysterectomy is still done via the abdominal route (63 per cent) or the vaginal route (23 per cent). Just 9.9 per cent of hysterectomy is conducted laparoscopically [5.6]. solution has its benefits, its drawbacks and its limitations. The laparoscopic technique became generally recognized as an alternative to the conventional laparotomy.

Much of it studies compared the laparoscopic approach to either the standard laparotomy approach or the vaginal route.

In this research, the advantages of the use of LigaSure during open hysterectomy via a narrow abdominal incision $<6 \mathrm{~cm}$ in duration (minilaparotomy hysterectomy) were examined.

Standard minilaparotomy (group A) and minilaparotomy using LigaSure (group B) were associated with laparoscopic hysterectomy using LigaSure (group C). The mean operation period for minilaparotomy hysterectomy with ligaSure community was $55.31 \pm 7.81$ minutes, slightly less than the traditional minilaparotomy community $(84.71 \pm 9.91$ minutes) and laparoscopic method (94.81 \pm 16 minutes). This major disparity can be clarified by the simultaneous coagulation and cutting of both pedicles by LigaSure.

The mean operating period for traditional minilaparotomy was close to that recorded by Hoffman and Lynch (1998) (84 minutes). On the other side, it was longer than that recorded by Chalkoo et al. (2011) where the running period was 30, 41 and 45 minutes, respectively. This discrepancy in running period may be due to a slightly lower BMI in patients in other trials and also their use of uterine manipulators which facilitate the operation by delivering the uterus out through the small abdominal incision and this was not used in minilaparotomy in this study $[1,7]$.

Regarding the mean operative time in minilaparotomy hysterectomy with LigaSure group, it was shorter than that reported by Royo et al. (2009) [73.4 minutes] [8].

The length of procedure in the laparoscopy community was shorter than that recorded by Royo et al. (2009) [159.3 minutes], Drahonovsky et al. (2010) [111 minutes] and Roy et al. (2010) [100 minutes]. It should be remembered that the operational period in the laparoscopy community saw significant shortening with the occurrence of cases and a build-up of practice, beginning from 120-135 minutes. in the first cases and declining to reach 70-75 minutes in the last cases $[8,9,10]$.

As seen in Table (3), the mean approximate blood loss in the ligaSure minilaparotomy hysterectomy community was slightly smaller $(99.1 \pm$ $30.8)$ than in the traditional minilaparotomy community $(130.3 \pm 54.4)$ and the laparoscopy group $(128.6 \pm 6.6)$.

The operative area in Group B was virtually bloodless, rendering it safer and quicker to analyze. A slight volume of smoke has not blurred the vision. With regard to blood loss in the traditional minilaparotomy community, there is a broad variance in the literature. The mean blood loss in this sample was less than that reported by Mahendru et al. (2011) (240 ml) whereas it was more than recorded by Chalkoo et al. (2011) (20 $\mathrm{ml})$. One of the essential advantages of laparoscopic surgery is the visualization of anatomy and pathology, as well as convenient access. [1,11]. The mean blood loss in the laparoscopy community was lower than that recorded by Drahonovsky (2010) $(184 \mathrm{ml})$. It should be remembered that 2 instances of intraoperative bleeding have occurred in the laparoscopy community. In these 2 situations, the descending cervical branch of the uterine artery has slipped, and this necessitated a further implementation of the LigaSure bipolar channel sealing device without the requirement for conversion to laparotomy or blood transfusion [9].
As a consequence of blood loss, table (4) reveals that the mean hemoglobin deficiency 12 hours after operation was slightly smaller in the ligaSure minilaparotomy community $(0.49 \pm 0.2 \mathrm{gm} / \mathrm{dl})$ than in the laparoscopy community $(0.68 \pm 0.5 \mathrm{gm} \mathrm{/} \mathrm{dl})$ and the standard minilaparotomy group $(0.71 \pm 0.25 \mathrm{gm} / \mathrm{dl})$.

The mean pain level (revised face pain scale) as seen in Table [5]. was significantly higher $(5.2 \pm 1.1)$ in comparison to that in minilaparotomy hysterectomy with LigaSure group (3.8 \pm 1.6$)$ and laparoscopy group (3.7 \pm 1.2 ). These results are similar to that reported by Royo et al. (2009) who reported no difference in pain scores between minilaparotomy hysterectomy (using LigaSure) or laparoscopic hysterectomy [8]. As reported by Marana et al. in 2003, minilaparotomy can elicit a neuroendocrinal response less than laparotomy and similar to laparoscopy due to the use of fine instruments and small abdominal wall retractors $[11,12]$.

As shown in table [5], the mean duration of hospital stay in conventional minilaparotomy group was significantly longer $(31.8 \pm 5.7$ hours $)$ than that in the minilaparotomy hysterectomy with LigaSure group $(20.7 \pm 2.3$ hours) and laparoscopic hysterectomy group (19.3 \pm 6 hours).

This significant difference was noticed in most of the studies in the literature.

Throughout the study, it was our trend to discharge patients in the next morning after being sure of sound uneventful postoperative course. This resulted in a dramatic fall in duration of hospital stay from days to hours.

There were no major intraoperative or postoperative complications except one case of bladder injury in group $\mathrm{C}$. These data favour adoption of this approach. It is to be mentioned that Chalkoo et al. (2011) confirmed in their study that this strategy is safe and only the complicated cases need prolonged hospital stay. There is no doubt that reduced hospital stay has its implications on the cost savings to medical systems [1].

As shown in table [6], the complication rate in all groups was very low. No intraoperative complications were encountered in group A or B. only one case of bladder injury was encountered in the first case of group C during sharp bladder dissection. The injury was immediately recognized and repaired. Short and long term follow up of this case was unremarkable.

Overall, the study had a low rate of postoperative complication. In the conventional minilaparotomy hysterectomy group, there was a case of stitch sinus and 3 cases of serum formation, while seroma occurred in 2 cases of minilaparotomy hysterectomy in the LigaSure group. All of these patients underwent frequent dressing with sound healing without the need for a readmittance or additional antibiotic treatment. The complication rate in this study was comparable to that reported by Mehendru et al. (2011), while it was less than that reported by Sharma et al. (2004) [3,11].

It is to be noted also that the random allocation of patients according to their desire after counseling was a contributor to the difficulties met in some cases during the study.

\section{Conclusion}

Minilaparotomy hysterectomy with ligas may be an appropriate effective alternative to laparoscopic hysterectomy, combining the technical advantages of laparotomy (e.g. short learning curve than laparoscopic) and the convalescent advantages of laparoscopic surgery (low morbidity, short hospital stay and good cosmetic results). So, it can be ideal in areas where high laparoscopic experience is and laparoscopic hysterectomy are 
considered safe in terms of intraoperative and postoperative complications.

\section{References:}

1. Chalkoo M, Ahangar S, Durrani AM, et al. (2011): Minilaparotomy hysterectomy-revisited with new concepts and technical modifications. International Journal of Surgery; 9: 404-409.

2. Munro, M.G.; Brill, A.I. and Parker, W.H. (2007): Gynecologic endoscopy. In: Berek and Novak's Gynecology (14th edition); 2(21): 749-804.

3. Sharma JB, Wadhwa L, Malhotra M, et al. (2004): Minilaparotomy versus conventional laparotomy for abdominal hysterectomy: A comparative study. Indian J. Med. Sci.; 58: 196-202.

4. Pelosi MA II and Pelosi MA III (2003): Pelosi minilaparotomy hysterectomy: Effective alternative to laparoscopy and laparotomy. J Am Assoc Gynaecol Laparosc.

5. Farquhar, C. and Steiner, C.A. (2002): Hysterectomy rates in the United States 1990-1997. Obstet Gynecol; 99: 229-234.

6. Advincula AP and Falcone T. (2008): Minimally invasive gynecologic surgery; Nezhat operative gynecologic laparoscopy and hysteroscopy 3 rd ed ;23;23.2(567-576).
7. Hoffman MS and Lynch CM (1998): Minilaparotomy hysterectomy. Am J Obstet Gynecol; 179: 316-320.

8. Royo P, Alcazar JL, Manero MG, et al. (2009): The value of minilaparotomy for total hysterectomy for benign uterine disease: A comparative study with conventional Pfannenstiel and laparoscopic approaches. International Archives of Medicine; 2: 11.

9. Drahonovsky J, Haakova L, Otcenasek M, et al. (2010): A prospective randomized comparison of vaginal hysterectomy, laparoscopically assisted vaginal hysterectomy, and total laparoscopic hysterectomy in women with benign uterine disease. European Journal of Obstetrics and Gynecology and Reproductive Biology; 148: 172-176.

10. Roy KK, Goyal M, Singla S, et al. (2010): A prospective randomized study of total laparoscopic hysterectomy, laparoscopically assisted vaginal hysterectomy and nondescent vaginal hysterectomy for the treatment of benign diseases of the uterus. Arch Gynecol Obstet.

11. Mahendru R, Malik S and Mittal A (2011): Minilaparotomy hysterectomy: A worthwhile alternative. J. Obstet. Gynaecol. Res.; 37(4): 305-312.

12. Marana E,Scambia G,Maussier ML,et al. (2003): Neuroendocrine stress response in patients undergoing benign ovarian cyst surgery by laparoscopy,minilaparotomy and laparotomy. J Am Ass Gynecol Laparosc; 10:159-165.
This work is licensed under Creative Commons Attribution 4.0 License

To Submit Your Article Click Here: Submit Article

DOI:10.31579/2642-9756/037
Ready to submit your research? Choose Auctores and benefit from:

* fast, convenient online submission

* rigorous peer review by experienced research in your field

* rapid publication on acceptance

* authors retain copyrights

* unique DOI for all articles

* immediate, unrestricted online access

At Auctores, research is always in progress.

Learn more https://www.auctoresonline.org/journals/women-health-careand-issues 